\title{
Research on the Affect of Earthquake Disaster Publish Schedule on
}

\section{Earthquake Relief}

\author{
Bin Yang ${ }^{1}$ \\ ${ }^{1}$ Earthquake Administration of Shanxi Province, Taiyuan, Shanxi, 030021
}

KEYWORDS: Earthquake Relief; Earthquake Publish Time; Social Development

\begin{abstract}
The timely Published of earthquake is reflected in the face of national disaster emergency rescue capabilities. In this paper, the use of the death toll reported time as a measure to evaluate the earthquake rescue capability. Combined with China's actual situation, analyze the aspects and factors influencing earthquake rescue operations, and their impact on relief operations possible in order to provide a useful complement to the theory and practice of earthquake relief.
\end{abstract}

\section{Introduction}

In recent years, frequent natural disasters around the world in reported relief process, a number is the most number of deaths caused by disasters of attention, which reflects the life of the people and respect for the precious life (whether in the earthquake relief or flood wrecking ,, people-oriented, influence and guide our government and the army in the relief process has always been the top priority will be to save as (many scholars earthquake death laws were thought to explore a wide range of human life, and such decision the main factor earthquake final death toll, including the earthquake moment magnitude, intensity and population density. by analyzing nearly 400 seismic data, found that an important factor in the socio-economic levels also affect the number of earthquake deaths earthquake death time curve number were analytical model, the model Liu Cho et amended the same time, a large number of documents were qualitatively discussed the impact of the earthquake emergency relief effect, the main factor earthquake emergency, but relatively speaking, quantitative analysis related to disaster relief effect and assessment studies are rare (at present, at home and abroad on how to quantitatively characterize or evaluate the efficiency of earthquake relief is still not a unified standard was demonstrated that the shorter the death toll close to the total number of reported time, characterizing the rescue the stronger the conclusion illustrates the efficiency of disaster relief is a relational deaths and after the earthquake time to measure puts forward to when the death toll varying characteristics to measure the efficiency of disaster relief model, but they will be an earthquake relief efficiency as a constant, the main factors affecting the efficiency of the relief does not go into (as all changes earthquake death toll intention is to reduce the number of deaths as relief efficiency factors of influence, it is also to decision to provide relief for the earthquake relief headquarters of the reference levels, thereby increasing the efficiency of disaster relief (after an earthquake, major media and relevant bodies will release the physical parameters of the seismic attributes, such as magnitude, seismic intensity, geographical source location and depth of the casualties and other data (related to the earthquake area in addition humanities economic and environmental parameters, such as per capita GDF, population density, housing seismic situation and traffic conditions in the area can be obtained in addition to the text 
from the relevant website of the United Nations Social Sciences Related media rescue personnel, actual materials, and other inputs will have live coverage, study these numbers, both to understand the actual needs of the disaster situation, but also the ability to characterize the resulting earthquake rescue.

\section{The Basic Process of Rescue Response}

In the first analysis before rescue operations need to understand the factors that affect the process of rescue operations! Rescue equipment, techniques and methods of selection and determination is determined by the type of disaster and site environment! For rescue operations, every time rescue operations used equipment, techniques and methods may differ, but the rescue operation from the program on the whole is roughly the same as the international Search and rescue Advisory group will rescue operations in five phases: estimate the accident area; transferring the injured victims; collapse into the rubble to search by sleepy person; cleaning up debris and rescued trapped European international emergency technical Center presented SAVER rescue „, its essence is trapped close to the limited space and rescue people out of a systematic approach which consists of six steps. seven aspects: the arrived at the scene; risk assessment; create rescue channels; comforting victims; open space rescue; fixed transfer victims and up to the evaluation, the international Search and rescue Advisory group relief program includes two search and rescue operations, the international emergency technical Center rescue program will focus on a specific rescue operations combining the characteristics of international Search and rescue Advisory group and the international emergency technical Center rescue procedures and to consider China's actual situation, and sketched out a response for China earthquake relief operations process.

Earthquake Seismological Bureau released the report, make appropriate rescue team sent to prepare; decision-making institutions to collect disaster information, including location earthquake disaster scale.

Decision-making body issued the command to send the rescue team after receiving the dispatch orders and make dispatch operations and coordinate with other agencies to determine the affected motor way to reach; the disaster area after receiving the order, the establishment of the disaster site coordination centers and reception centers, do other good emergency preparedness. After reaching the disaster, the rescue team arrived to receive the mission area affected, the reception center reception rescue team arrived, the rescue team captain to receive the task focal area, and contact local authorities to determine the way to reach the mission area. After the rescue team arrived in the mission area, according to the plan to establish a base on the one hand, on the one hand to send personnel to the mission area reconnaissance, collect information, make a rapid assessment (the number of collapsed buildings in the area, type, structure and building materials to the mission area, the number and type of traffic hazards, potential victims information obtained from survivors there), information collected for analysis, make a dispatch policy; if the rescue team to complete the task within a maximum response time, send search and rescue teams and rescue team for action; if it can not complete the task within a maximum response time, in addition to dispatch search and rescue teams and rescue teams carry out operations, the need to request support coordination center. Search unit after receiving the task, according to expand the deployment of search efforts, if found survivors, you need to locate the survivors, and survivors and burying place dedicated mark, and the need to report the situation to the on-site command center, after completion of the task, continue search task, until all deployment tasks. After the on-site command center received the information search unit, to make the deployment of rescue forces, rescue squad if to complete the task, in accordance with the program of action to rescue the victims, after the end of the rescue operation, if 
the new rescue mission, the action for transitions If not, then be rest; Ruoyin personnel, equipment or other factors can not complete the rescue mission, the request to support.

\section{Earthquake Relief in the "Black Box" and "Gray Box"}

Earthquake has burst, the vast majority of casualties are trapped or buried in the loss down construction (structures), a part of itself off to save people through quickly leave the woods and buried with no pressure staff together whatever rescued the remaining staff, and the most difficult places to rescue the rescue later professional rescuers. Professional rescue workers need in a very short period of time, will be besieged, burying people rescued. The most effective relief time is on the first day after the earthquake, the 1976 Tangshan, China and Japan's Kobe earthquake in 1995. Statistics show that the first day rescued the survival rate was $81 \%$, while the next day the survival rate of only rescue personnel $31 \%$.

However, construction (structures) in the besieged, burying many people, how many people need to support this at the beginning of the earthquake to make an accurate judgment is quite difficult. Get outside assistance to the event of the earthquake stricken area from this time, called the rescue vacuum . Initially during the earthquake, the disaster information as a "black box", the outside world need to know about "disaster areas where the disaster much, how many victims, how many people died, how many people were injured, how many people are beginning to self-help and mutual aid, etc. "important information within the first few hours completely unaware of, which makes relief decision-making, how many people go to disaster relief dispatch instructions difficult to make. The disaster came from the casualties of the earthquake relief based on the collected data in time from the moment the earthquake shortest $1 \mathrm{~h}$, up to $17 \mathrm{~h}$, an average of $5.4 \mathrm{~h}$, mean square error of 3.9h. Even outside personnel into the disaster area, "black box" has been opened, but disaster information is still not perfect, it is still plagued by leadership high command. Take a few hours to several days, disaster information will gradually become clear. We call this period the "gray box." "Black box" and the length of the "gray box" Time is undoubtedly essential for improving the survival rate of personnel. "Gray box" later time called "white box", indicating that the disaster has basically mastered.

\section{The Earthquake Published Affect on Earthquake Relief}

In the early days of the devastating earthquake, the death toll announced by the media rarely, the presence of the death toll and later confirmed by the very different, leading reinforcements goods slowed. With the death toll released gradually increased, to cause widespread social attention, suddenly rising reinforcements and supplies. From 1995 to 2004, domestic and foreign 21 earthquake news release process statistics, found in the following two characteristics: the death toll reported the total number of deaths associated with time. Rescue personnel trapped in the rubble, the need for each house to clean up, search, rescue survivors and find victims are carried out simultaneously. Studies have shown that the number of deaths and injuries were reported to their respective time curve has presented good correlation. The more the number of deaths, the rescue will take longer. Earthquake death toll close to the total number of reported shorter the time, the stronger the ability to characterize the rescue. After excavation earthquake buried pressure staff time is limited, because the time for survivors in the rubble of survival is limited, the longer the time to dig, the more survivors hope of survival slim.

August 17, 19997.4 earthquake in Izmit, Turkey, 15,800 people died, the experience is 4.41d, plus all variance 5.43d, reported basic time $8.27 \mathrm{~d}$, beyond, as rescue poor persons; October 23, 
2004 Japan's new 7.0 earthquake, the death of 31 people, the experience is $0.33 \mathrm{~d}$, plus all variance $1.35 \mathrm{~d}$, reported basic time $1.89 \mathrm{~d}$, has been exceeded, but also as a poor person relief ; if the difference between the average value and the variance of experience or less, and the ability to rescue "strong" by, for example, February 24, 2003 BACHU China 6.8 earthquake, the death of 268 people, the experience is $1.74 \mathrm{~d}$, minus the mean square error $0.72 \mathrm{~d}$, reported basic time $0.28 \mathrm{~d}$, which should become a strong rescue capability. The rest is "in."

In this way, you can test out 24 earthquake rescue procedure in Table 1, four times a rescue capability as "poor", they are: August 17, 1999 7.4 earthquake in Izmit, Turkey, December 26, 2003 7.0 earthquake in Bam, Iran, November 12, 1999 Turkey Bolu 7.2 earthquake and October 23, 2004 new Japan County 7.0 earthquake; there are six rescue capability is "strong", they are: 1999 September 21 China Taiwan Nantou 7.6 earthquake, March 25, 2002 Afghan Hindu Kush 7.0 earthquake, February 24, 20046.5 earthquake in Al Hoceima, Morocco, February 13, 20016.6 earthquake in El Salvador , February 24, 20036.8 earthquake in Xinjiang Bachu China and June 22, 2002 Iran Qazvin Province 6.3 earthquake; the remaining 13 times rescue capability to moderate. So, you can use death toll reported time characterizing the strength of the earthquake rescue capability.

Earthquake death toll reported time, it plays an important role in earthquake relief. Reported earlier the outside world to understand more clearly the earthquake, followed by rescue personnel and relief supplies into the affected areas, the earlier time, disordered state disaster areas can be restored as soon as possible; on the contrary, reported the later time, the outside world did not understand the truth of the disaster, the earthquake relief headquarters difficult to resolve delegated adequate rescue personnel and provide a wealth of relief supplies, lack of foreign aid the disaster area, the disorder will be extended.

\section{Conclusion}

If you want relief efficiency more accurate calculation, in addition to the time of earthquake occurrence described in the article should be considered, the quality level of rescue teams, disaster occurred ecological geography, government capacity to respond, and social factors were explored.

\section{Acknowledgements}

Project: Earthquake Industry Special Scientific Research Projects (NO. 201208018); Basic Research Project in Shanxi Province (NO. 2012021017; The Earthquake Science and Technology Spark Plan Project (NO. XH14009Y); Seismological Bureau of Shanxi Province Youth Project (NO.SBK-1634); The Young Earthquake Emergency Key Tasks (CEA_EDEM-201403).

\section{References}

[1] Allen R E. Automatic earthquake recognition and timing from single traces [J]. Bulletin of the Seismological Society of America 1978, 68 (5): 1521-1532.

[2] Anderson, K. R., Epicentral location using arrival time order [J]. Bulletin of the Seismological Society of America Vol.70, No.2, 1981:.. (541-545).

[3] Andrew B. Lockman and Richard M. Allen Magnitude-period scaling relations for Japan and the Pacific Northwest:. Implications for earthquake early warning [J]. Bulletin of the Seismological Society of America, Vol 97, No. 1B,.. pp 140-150, February 2007, doi: 10.1785 / 0120040091.

[4] Andrew B. Lockman and Richard M. Allen. Single-station earthquake characteri- zation for 
early warning $[\mathrm{J}]$. Bulletin of the Seismological Society of America, Vol. 95, No. 6, pp. 2029-2039, December 20051. 